\title{
Clustering of minor psychiatric disorders and burden among family caregivers of individuals with mental illness
}

\author{
Clusterização de transtornos psiquiátricos menores e sobrecarga \\ entre familiares cuidadores de pessoas com transtornos mentais
}

\author{
Carlos Alberto dos Santos Treichel ${ }^{1}$ \\ Vanda Maria da Rosa Jardim ${ }^{1}$ \\ Luciane Prado Kantorski ${ }^{1}$ \\ Mariana Luchese Vasem ${ }^{1}$ \\ Aline dos Santos Neutzling ${ }^{1}$
}

${ }^{1}$ Departamento de Enfermagem, Faculdade de Enfermagem e Obstetrícia, Universidade Federal de Pelotas. R. Gomes Carneiro 1, Porto. 96010-610 Pelotas RS Brazil.carlos-treichel@ hotmail.com

\begin{abstract}
The objective of this cross-sectional study is to analyze the relationship between minor psychiatric disorders, burden and other associated factors among family caregivers of people with mental disorders. The study was conducted with 1164 relatives of users of the Centers for Psychosocial Care in southern Brazil, and for screening of minor psychiatric disorders, the Self-Reporting Questionnaire (SRQ20) scale was used, based on its Brazilian validation with an adopted cutoff point of 6/8. Even though previous studies have appointed the burden arising from care as protagonist in the presentation of minor psychiatric disorders, a clustering based on log-likelihood by Bayesian Information Criterion conducted in this study found that burden is not the only possible predictor for emotional/mental illness, suggesting that other factors permeate this relationship. Thus, bivariate analyzes were conducted, in which the influence of variables such as health problems, work issues, among others, can be observed in different groups arranged by the cluster.
\end{abstract}

Key words Minor psychiatric disorders, Caregivers, Communitary mental health services, Burden, Cluster
Resumo Este estudo transversal objetiva analisar a relação entre os Transtornos Psiquiátricos $\mathrm{Me-}$ nores, sobrecarga e outros fatores associados em familiares cuidadores de pessoas com transtorno mental. O estudo foi realizado com 1164 familiares de usuários de Centros de Atenção Psicossocial do Sul do Brasil e utilizou para rastreamento de Transtornos Psiquiátricos Menores a escala Self-Reporting Questionnaire (SRQ20) tendo como base a validação brasileira da escala que adotou como ponto de corte 6/8. Embora estudos prévios tenham apontado a sobrecarga advinda do cuidado como protagonista na apresentação de Transtornos Psiquiátricos Menores, uma clusterização baseada em Verossimilhança de Log pelo critério Bayesiano de Schwarz conduzida nesse estudo apontou que sobrecarga não seria o único preditor possivel para o adoecimento emocional/psíquico, sugerindo que outros fatores permeiam essa relação. Sendo assim, análises bivariadas foram conduzidas, pelas quais se podem observar influência de variáveis como problemas de saúde, questões de trabalho entre outras nos diferentes grupos dispostos pelo cluster.

Palavras-chave Transtornos Psiquiátricos Menores, Cuidadores, Serviços comunitários de saúde mental, Sobrecarga, Cluster 


\section{Introduction}

Given the process of psychiatric deinstitutionalization experienced by Brazil in recent decades, several changes occurred in regard to the factual process of care provided to people with mental disorders. The individual in psychological distress, previously segregated and excluded from social contact, is brought out of the asylum, and reinserted in society ${ }^{1}$.

Among the framework of changes caused by this process, the difference in the perception of the family is without doubts one of the main changes in this scenario. During the history of psychiatry, the family was either seen as the cause of this disease, reinforcing the need for isolation, or seen as an accomplice, allowing the institutionalization of the patient ${ }^{2}$.

However, understanding that the care is only possible when considering the environment and existing resources to care for the patient $t^{3,4}$, the family is inserted in the care and now features as one of its protagonists.

As caregivers, the relatives encounter multiple and challenging tasks every day, ranging from the acceptance of the diagnosis, administration of family conflict and the reprogramming of the future - facing the disruption of the family structure caused by the possible modification of social roles ${ }^{5,6}$. It should also be noted, that the family is often not prepared to deal with the situation of disease in one of its members. And even with their positive feelings towards the family, cannot deal with their emotions when facing a reality of doubts and uncertainties ${ }^{4,7}$.

Because of that, many relatives may experience feelings of depression and anxiety, causing negative consequences in the context of family, social relations and work ${ }^{8}$.

These cases of anxiety and depression can be classified as minor psychiatric disorders (MPD), once they do not meet all the criteria of mental illness according to the International Classification of Diseases (ICD-10). Expanding this understanding, we can say that the MPD relate to health conditions involving non-psychotic psychiatric symptoms, such as insomnia, fatigue, irritability, depression, anxiety, forgetfulness and difficulty concentrating.

The MPD among family caregivers have been addressed by previous works ${ }^{5,6,8}$, which most often feature associations of MPDs and burden arising from the caregiver role. However, considering the magnitude of the aspects that permeate the care relationship, it is necessary to constantly rethink the root of such problems, since these caregivers are individuals who also demand attention from the health care network, that should be capable to act and intervene effectively.

Thus, this paper aims to analyze the relationship between the MPD, burden and other associated factors among family caregivers of individuals with mental disorders in order to establish a more accurate picture of this scenario.

\section{Methodology}

This is a cross-sectional study carried out with 1164 relatives of people with mental disorders, clipping of a community-based mental health service evaluation research in southern Brazil, entitled CAPSUL II and held in 2011.

In order to determine the prevalence of minor psychiatric disorders in the sample, this study considered the Self-Reporting Questionnaire (SRQ20) scale for screening. Developed by Harding et al. ${ }^{10}$ and validated in Brazil by Mari and Williams ${ }^{11}$, this instrument was proposed by the World Health Organization for the detection of minor psychiatric disorders in the population.

The scale consists of twenty questions with yes/no answers, and according to Harding et al..$^{10}$, the cut-off point, number of positive questions that determine the presence of a minor psychiatric disorder, has a considerable variation from $5 / 6$ to $10 / 11$, depending on the cultural context in which it is applied, including place and time. This study used as model the Brazilian validation, in which Mari and Williams ${ }^{11}$ found a sensitivity and specificity of $83 \%$ and $80 \%$ respectively when used as cut-off point $6 / 8$, being the first number the cutoff point for men and the second for women.

Considering the review of literature and the borders of study theme, some variables of sociodemographic data, health conditions and caring aspects were included in this research. In particular, the feeling of burden, which was set as important defining cause of minor psychiatric disorders.

Data collection occurred with the use of a pre-structured questionnaire and happened in 40 services distributed in the three southern states of Brazil. Quality control was performed upon the receipt of the collection instruments by checking each interviewer; by the review conducted by supervisors to receive the questionnaires; and by the replication of $5 \%$ of interviews and correcting the coding. 
The data went through double entry in the software EPI-INFO,differences between information were compared and evaluated. The same database was used for corrections when needed.

The study protocol was approved under technical opinion No. 176/2011, by the Ethics Committee of the Faculty of Nursing of the Federal University of Pelotas following the Standards and Guidelines for the Regulation of Research Involving Human Beings - CNS Resolution $196 / 96$, the aspects this study also conform to the CNS 466/2012 resolution. Ethical principles were secured by: informed consent; guarantee of the right not to participate in the study and confidentiality of information.

Data analysis was performed using the softwares STATA 11 (Stata Corp., College Station, USA) and IBM SPSS Statistics. Given the relationship established in literature between the burden and the outcome of minor psychiatric disorders in order to classify the sample according to their behavior in relation to these characteristics, the relatives were divided into 4 groups arranged by clustering based on log-likelihood by Bayesian Information Criterion. Bivariate analyzes were conducted to characterize the groups, with statistical significance assessed by Chi-square test, adopting as significant a $\mathrm{p}$-value $\leq 0.05$.

\section{Results}

The clustering of the sample according to the feeling of burden and the presence of minor psychiatric disorders has split it into 4 groups as shown in Table 1.

Analyzing Table 1, it is possible to point out that the two largest groups generated represent similar proportions of the sample, they are the groups 1 and 4 that constitute $32.4 \%$ and $32.1 \%$ of relatives respectively.

Table 1. Distribution of the sample according to the grouping defined by the likelihood ratio of burden and minor psychiatric disorder.

\begin{tabular}{cccc}
\hline Group & $\%(\mathbf{N})$ & Feeling of Burden & MPD \\
\hline Group 1 & $32,4(377)$ & Absent & Absent \\
Group 2 & $20,7(241)$ & Present & Absent \\
Group 3 & $14,8(172)$ & Absent & Present \\
Group 4 & $32,1(374)$ & Present & Present \\
\hline
\end{tabular}

Source: CAPSUL, 2011.
Group 1 is characterized by individuals who did not have feelings of burden and were not screened as minor psychiatric disorder cases, on the other hand, Group 4 consists of individuals who presented burden and were screened positive for minor psychiatric disorders.

Groups 2 and 3 are made of a minor proportion of the sample, however, it is worth mentioning that they represent different conditions. The first, corresponding to $20.7 \%$ of relatives that feel burdened but do not have a minor psychiatric disorder, and the latter, consisting of the other $14.8 \%$ of the sample, representing the subjects that screened positive for a minor psychiatric disease even if not feeling burdened.

The results of the bivariate analysis conducted to raise possible explanations for the different associations between feelings of burden and minor psychiatric disorders expressed in the group, are shown in Table 2.

It is observed that there was a statistically significant difference between groups in all the selected variables, suggesting that the average response for each variable was different in each group, thus validating the cluster found.

Among the groups in which individuals were screened as positive cases of minor psychiatric disorder - Groups 3 and 4 - women accounted for $70.93 \%$ and $74.33 \%$ of subjects respectively. The results regarding the individual's family tie to the patient expressed association between the proximity of the bond and the outcomes Burden and MPD. Comparing Groups 1 and 4, which in theory would be the most distant groups due to their different behavior for both burden and minor psychiatric disorder, it is observed that the Group 4-more affected - tend to have the closest affiliation with the patient.

It is possible to observe that Groups 3 and 4 , where the minor psychiatric disorders are present, not having a paid work appeared more strongly than in other groups.

The proportion of health problems had an inverse relationship between Groups 1 and 4, which correspond to the least and most affected individuals respectively. In Group 1 where no manifestation of MPD and burden were found, most of the sample $(59.68 \%)$ did not have a health problem. On the other hand, Group 4, which has both burden and minor psychiatric disorders, the majority (68.98 \%) of the relatives presented health problems. As to Group 3, it is possible to point out that even if not expressing feelings of burden, the individuals in this group were screened as positive case of minor psychiat- 


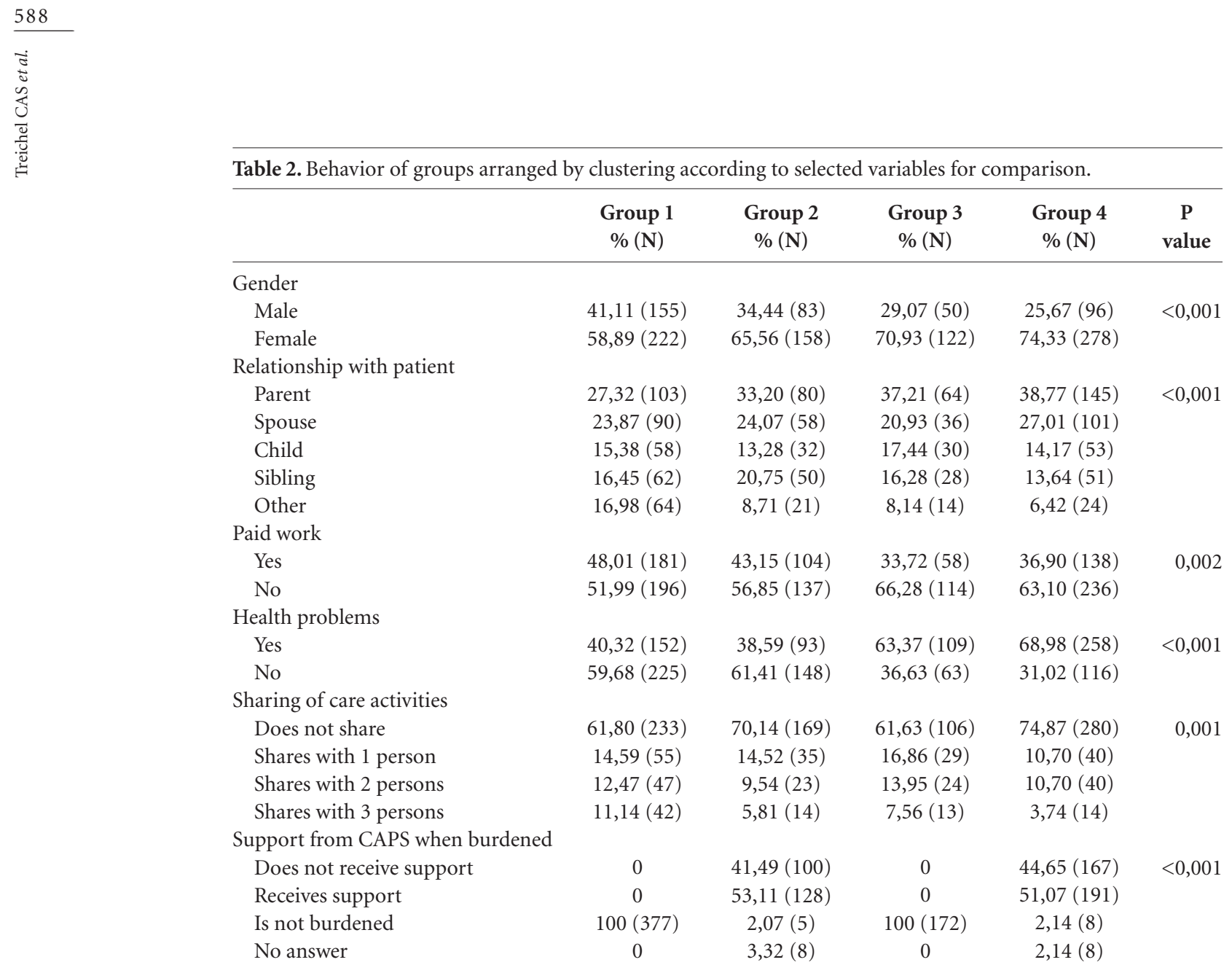

Source: CAPSUL, 2011.

ric disorder. In this group, a portion corresponding to $63.37 \%$ of family caregivers reported having health problems.

Although in the four groups there are individuals who take care of their ill relative alone, the groups where caregivers have feelings of burden have the greater proportions of this characteristic. In Group 4, 74.84\% of subjects are the only caregivers of the patient, in the same sense, in Group 2, individuals who do not share the care activities correspond to $70.14 \%$.

Individuals who reported burden were asked about the support they receive from CAPS (Centers for Psychosocial Care) when they feel burdened, being so, only individuals from Groups 2 and 4 answered this question. Among the individuals in Group 2, 53.11\% reported receiving support, as to the Group 4, those who received support accounted for $51.07 \%$ of the subjects.

\section{Discussion}

A number of studies have explored the minor psychiatric disorder as one of care's implications. In general, this approach is related to the burden, which in some studies assume the role of related factor $^{8,12,13}$ and in others of possible causal factor $^{5,14}$.

In order to understand this relationship, it is possible to observe in this study that the burden alone is not sufficiently explanatory as the cause of minor psychiatric disorders. Because if it were so, burdened individuals would necessarily present disorders while not burdened people would not. However, this study also confirms the existence of family members that even being burdened, did not have the disorders. And others still not presenting themselves with burden, demonstrated the presence of minor psychiatric disorders.

Having characterized the sample according to the outcome of burden and minor psychiatric disorders, it can be seen that $32.4 \%$ (377) of family caregivers had neither outcomes. In this group 
there was a higher presence of males in comparison to other groups, in addition to an increased presence of individuals who have a more distant bond to the user than first degree. Proportionally, it was the group that included most individuals who work and individuals who share the care with other caregivers.

On the other hand, in the group that concentrated individuals who manifested both burden and minor psychiatric disorders, these characteristics appeared virtually opposite. In this group it can be observed a greater presence of women among the relatives, as well as a greater concentration of individuals who have first-degree ties to the user. Family members of this group also corresponded to those who proportionately least shared the care activities and had most health problems.

It can also be pointed out that in the group where individuals were burdened and had MPD, the proportion of individuals receiving support from CAPS when burdened was lower than in the group whose relatives even if overloaded, did not show minor psychiatric disorders. It is inferred then that the support from CAPS in burden can make a difference in the outcome of minor psychiatric disorders.

However, it must be noted that there are other characteristics that differentiate these groups. In the group whose relatives did not have minor psychiatric disorders even if burdened, there is a higher prevalence of men and individuals who have a paid work.
The burden in this group can be attributed to the fact that the second group where family members least share the care. Nevertheless, this was the group where subjects received most support from CAPS, and maybe could cope better with the care activities, without getting sick emotionally/psychologically. This was the group where individuals had proportionally the least health problems, different from the group where subjects showed minor psychiatric disorders even if not burdened.

In the group where individuals had no feelings of burden, but appeared as positive cases of minor psychiatric disorder is possible to highlight the high prevalence of females, with first degree bonds. However, the absence of overload in this group can be attributed to the fact that this was the group that had individuals who proportionally most shared the care.

Yet, it is emphasized that this is the group where many subjects had health problems and fewer had a paid work. Assuming that there is a relationship between these two variables, this is an outcome that can be understood as a source of frustration for those family members, who developed a minor psychiatric disorder.

Considering these findings, it is emphasized that the profile of caregivers, issues related to employment, health, care and support, seem to permeate minor psychiatric disorders as well as burden. Thus, suggesting that the burden is not the only possible predictor for emotional/mental illness.

\section{Collaborations}

CAS Treichel, VMR Jardim, LP Kantorski, ML Vasem collaborated equally in all stages of preparation of the article and AS Neutzling collaborated in the analysis of results. 


\section{References}

1. Jorge MS, Pinto DM, Quinderé PH, Pinto AG, Sousa FS, Cavalcante CM. Promotion of Mental Health Technologies for Care: emotional involvement, reception, co-responsibility and autonomy. Cien Saude Colet 2011; 16(7):3051-3060.

2. Camatta MW, Schneider JF. The work of the staff of a Center for Psychosocial Care in the family perspective. Rev esc enferm USP 2009; 43(2):393-400.

3. Brazil. Ministry of Health $(\mathrm{MH})$. Department of Health Care. Department of Programmatic Strategic Actions. Mental health in SUS: the centers for psychosocial care. Brasília: MH; 2004.

4. Oliveira RMP, Loyola CM. Psychiatric Patient family: a conspicuous unknown portrait. Acta Scientiarum. Health Sciences 2004; 26(1):213-222.

5. Silva CF, Passos VMA, Barreto SM. Frequency and impact of the burden on family caregivers of elderly with dementia. Rev bras geriatr Gerontol 2012; 15(4):707731.

6. Marques AK, Landim FL, Collares PM, de Mesquita RB. Social support in the family caregiver experience. Cien Saude Colet 2011; 16(Supl. 1):945-955.

7. Pinto JMS, Nations MK. Care and chronic illness: family caregiver's viewpoint in Northeast Brazil. Cien Saude Colet 2012; 17(2):521-530.

8. Bandeira M, Calzavara MCP, Castro I. Burden of care in relatives of psychiatric patients: Validity study of the Family Burden Interview Scale. J bras Psiquiatr 2008; 57(2):98-104,

9. Tavares JP, Beck CLC, Magnago TSBS, Greco PBT, Prestes FC, Silva RM. Scientific production on the minor psychological distress from the Self-report questionnaire. Rev Enferm UFSM 2011; 1(1):113-123.
10. Harding TW, de Arango MV, Baltazar J, Climent CE, Ibrahim HH, Ladrido-Ignacio L, Murthy RS, Wig NN. Mental disorders in primary health care: A study of the frequency and diagnosis in four developing countries. Psychol Med 1980; 10(2):231-241.

11. Mari JJ, Williams PA. Validity study of a psychiatric screening questionnaire (SRQ-20) in primary care in the city of Sao Paulo. BJP 1986; 148:23-26.

12. Gavrilova SI, Ferri CP, Mikhaylova N, Sokolova O, Banerjee S, Prince M. Helping carers to care--the 10/66 dementia research group's randomized control trial of a caregiver intervention in Russia. Int J Geriatr Psychiatry 2009; 24(4):347-354.

13. Morais HC, Soares AM, Oliveira AR, Carvalho CM, da Silva MJ, de Araujo TL. Burden and modifications in life from the perspective of caregivers for patients after stroke. Rev Lat Am Enfermagem 2012; 20(5):944-953.

14. Quadros LC, Gigante DP, Kantorski LP, Jardim VM. Minor psychiatric disorders in family caregivers of users of Psychosocial Care Centers in southern Brazil. Cad Saude Publica 2012; 28(1):95-103.

Artigo apresentado em 26/03/2015

Aprovado em 16/06/2015

Versão final apresentada em 18/06/2015 